\title{
Ocorrência de epidemia do mal das folhas em regiões de "escape" do Brasil
}

\section{Occurrence of South American leaf blight epidemic in escape zones of the Brazil}

\author{
Edson Luiz Furtado ${ }^{*}$, Antonio Ribeiro da Cunha', Clayton Alcarde Alvares', João Alberto Zago Bevenuto', \\ José Raimundo Passos ${ }^{1}$
}

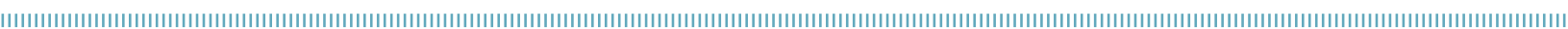

RESUMO: Entre janeiro e fevereiro de 2013 ocorreu uma epidemia de mal das folhas em regiôes consideradas como de "escape" à doença, causando preocupaçóes e indagaçóes nos produtores de borracha e ao setor heveícola como um todo. Uma possível adaptação do fungo a essas zonas foi levantada e a consistência do controle da doença pela utilização do binômio plantas com troca uniforme das folhas + período seco, típicos de regiôes de "escape", foi questionada. O objetivo deste trabalho foi trazer informaçôes importantes aos heveicultores sobre a interação clima-patógeno-hospedeiro e comparar variáveis de normais climatológicas (média histórica) e dados climáticos deste período de ocorrência da epidemia (janeiro e fevereiro de 2013). Concluiu-se que não foi o patógeno que se adaptou às plantas de seringueira em clima mais seco, nas regióes de "escape", mas que o clima mais úmido ocorreu nessas regióes mais secas, nesse período.

PALAVRAS-CHAVE: seringueira; clima; Microcyclus ulei.

\begin{abstract}
In January and February 2013 occurred a South American leaf blight epidemic in regions considered as escape zones, causing concern to rubber tree growers and throughout the rubber industry. A possible adaptation of the fungus to escape zones was raised and the consistency of disease control by the use of the binomial: plants with uniform renewal of leaves + dry season, typical of the escape zones, was questioned. The aim of this work was to bring relevant information to the rubber growers about the interaction climate-pathogen-host and to compare normal climate (historical average) and climatic data of the occurrence period of epidemic (January and February 2013). We conclude that was not the pathogen that has adapted to rubber tree in drier conditions, typical in escape regions, but a more humid climate occurred in these drier regions during this period.
\end{abstract}

KEYWORDS: rubber tree; climate; Microcyclus ulei. 
O mal das folhas é a doença mais importante para o cultivo de seringueira nas Américas e o Microcyclus ulei, o agente causal, é considerado como um dos patógenos foliares que mais prejuízos causaram, em comparação com outros patógenos que afetam as plantas cultivadas no mundo.

Os primeiros plantios comerciais de seringueira na América do Sul foram implantados em Trinidad, na Guiana e no Suriname, por iniciativa da Inglaterra, no início do século XX, em busca de diversificação agrícola e redução da dependência econômica, que essas colônias tinham, em relação ao açúcar.

Os plantios atingiram o seu apogeu em 1916, com 2.000 ha na Guiana, 1.000 ha no Suriname, além de 500 ha em Trinidad. Um pouco antes, no Suriname, um tipo de doença foliar, ainda desconhecida, espalhara-se como fogo entre as mudas, desfolhando-as. Mesmo sem a identificação do agente, tentou-se, sem êxito, a inoculação em outras espécies de plantas, demonstrando-se tratar de um parasita específico de Hevea. A sua descrição foi efetuada, em 1904, por Paul Hennings, que o denominou por Dothidella ulei. Em 1962, os micologistas Müller e Von Arx fizeram a revisão do gênero e o reclassificaram para Microcyclus ulei, nome que foi amplamente aceito. A doença por ele causada foi denominada por "mal sul-americano das folhas", ou simplesmente "mal das folhas".

No Brasil, os plantios da Ford Motor Company ficaram muito famosos, não pela borracha produzida, mas pelas epidemias de mal das folhas, que dizimaram as plantaçôes da empresa em Fordlândia e Belterra, em 1927 e 1940, respectivamente. O mesmo ocorreu em outras plantaçóes do litoral da Bahia e de Sáo Paulo. Depois disso, o Programa de Incentivo à Produção de Borracha Vegetal (PROBOR), um projeto financiado pelo governo brasileiro em busca da autossuficiência em borracha natural, dos anos 1970 até a metade dos anos 1980, teve a maior parte desses plantios dizimada pelo $M$. ulei.

A experiência paulista com a doença rendeu informaçóes importantes, pois, por iniciativa do coordenador do programa paulista, o Engenheiro Agrônomo João Jacob Hoelz, as mudas que seriam destruídas, para a erradicação do patógeno, foram distribuídas a produtores de outras regiôes mais secas do estado de São Paulo. Tal regiáo incluiu o centro, o norte e o noroeste do Planalto Paulista. Os plantios dessas regiôes transformaram-se em polos de observação. Nesses locais a epidemia do mal das folhas simplesmente não ocorreu e a renovação foliar, das plantas adultas, coincidiu com os meses mais secos do ano (julho-agosto). Nessas condiçôes o fungo não encontrou condiçôes para a infecção.

Desses campos de observação foi cunhado o termo "regiôes de escape", que tecnicamente significa: áreas de evasão, ou seja, um princípio geral de controle, que envolve o deslocamento do hospedeiro de regiôes com clima favorável à epidemia para outras com clima desfavorável. Foi o que aconteceu com a seringueira no Planalto Paulista, pois nessa região a seringueira se desenvolveu, produziu bem e permaneceu livre da epidemia do mal das folhas. Esses resultados de sucesso observados no
Planalto Paulista auxiliaram o zoneamento climático para a cultura no estado de São Paulo e depois para o país.

O conceito "zonas de escape" foi rapidamente disseminado. Várias regiôes brasileiras que apresentavam as mesmas características do Planalto Paulista foram vistas como promissoras para a heveicultura, como: sudeste de Mato Grosso, nordeste de Mato Grosso do Sul, noroeste de Minas Gerais, Goiás e Tocantins. Nessas regióes os plantios têm sido ampliados e vários polos de produção de borracha foram constituídos, principalmente nas quatro primeiras regióes.

A dúvida dos plantadores com relaçáo à adaptaçáo do fungo ao clima seco dessas regióes sempre persistiu. Porém, no início de 2013, nos meses de janeiro e fevereiro, foi evidenciada uma epidemia de mal das folhas nas regióes citadas acima: SP, MS, MT e GO. O fato trouxe apreensão a diversos heveicultores e gerou dúvida quanto ao futuro das plantaçôes.

Dessa forma, o objetivo deste trabalho foi trazer informaçóes importantes aos heveicultores sobre a interação clima-patógeno-hospedeiro e comparar variáveis climáticas importantes de normais climatológicas (1961-1990) e dados meteorológicos do período de ocorrência da epidemia (janeiro e fevereiro de 2013), a partir de estaçóes climáticas de diferentes municípios de SP, MS, MT e GO, no local, ou próximas às principais regióes de plantio desses estados.

Foram analisadas climaticamente as regióes de Votuporanga (SP), Três Lagoas (MS), Itiquira (MT), Rondonópolis (MT), Cuiabá (MT), Jataí (GO), Rio Verde (GO), Goiânia (GO) e Goiás (GO) (Fig. 1), das quais são apresentados: as localizaçôes geográficas, o tipo de clima, as normais climatológicas e o clima observado entre janeiro e fevereiro de 2013, representado por temperatura do ar (T), umidade relativa (UR) e precipitaçáo $(\mathrm{P})$ de cada regiáo (Tabela 1). Os dados horários entre 12 de janeiro e 10 de fevereiro de 2013 foram obtidos do site do Instituto Nacional de Meteorologia (INMET, 2013), e as normais climatológicas, do INMET (2009). A classificação climática de Köppen de cada localidade foi obtida do mapeamento nacional apresentado por Alvares et al. (2013). Compararam-se as normais climatológicas com os dados obtidos entre janeiro e fevereiro de 2013, período em que ocorreu a epidemia.

Estabeleceu-se a duração do período de molhamento (DPM) como sendo o número de horas de UR igual ou maior que $90 \%$ (DPM = NHUR $\geq 90 \%$ ) (Sentelhas et al., 2008).

Visando resumir e visualizar melhor as informaçôes referentes a T, a UR e a P ocorridas nas regióes analisadas, determinou-se a distribuição da frequência diária, no período entre 12 de janeiro e 10 de fevereiro de 2013, do número de horas de temperatura do ar (NHT) no intervalo entre $20 \mathrm{e}$ $25^{\circ} \mathrm{C}$, do número de horas de umidade relativa do ar (NHUR) igual ou maior que $90 \%$ e do número de horas de $\mathrm{P}$ (NHP) igual ou maior que $1 \mathrm{~mm}$ entre $00 \mathrm{~h} 00 \mathrm{~min}$ e $23 \mathrm{~h} 00 \mathrm{~min}$. Agruparam-se os dados por classes de ocorrência com base nas horas do dia: 4, 8, 12, 16, 20 e 24. 
Todas as regióes foram classificadas com o tipo climático Aw, ou seja, apresentam temperaturas do mês mais frio do ano superior a $18^{\circ} \mathrm{C}(\mathrm{A})$; a $\mathrm{P}$ do mês mais seco é menor que $60 \mathrm{~mm}$ - inverno seco $(\mathrm{m})$; o mês mais quente do ano tem temperatura superior a $22^{\circ} \mathrm{C}$ (Tabela 1$)$.

Observou-se que o índice pluviométrico aumentou consideravelmente no período entre 12 de janeiro e 10 de fevereiro de 2013 em relação aos dados normais (1961-1990) para o mesmo período nas regióes de Votuporanga (SP), Itiquira (MT), Rondonópolis (MT), Cuiabá (MT), Rio Verde (GO), Goiânia (GO) e Goiás (GO) (Tabela 1), com percentuais de 14, 78, 10, 6, 106, 80e 33\%, respectivamente. Destacam-se as regióes de Itiquira (MT), Rio Verde (GO) e Goiânia (GO), que apresentaram índices pluviométricos bem acima dos valores normais.

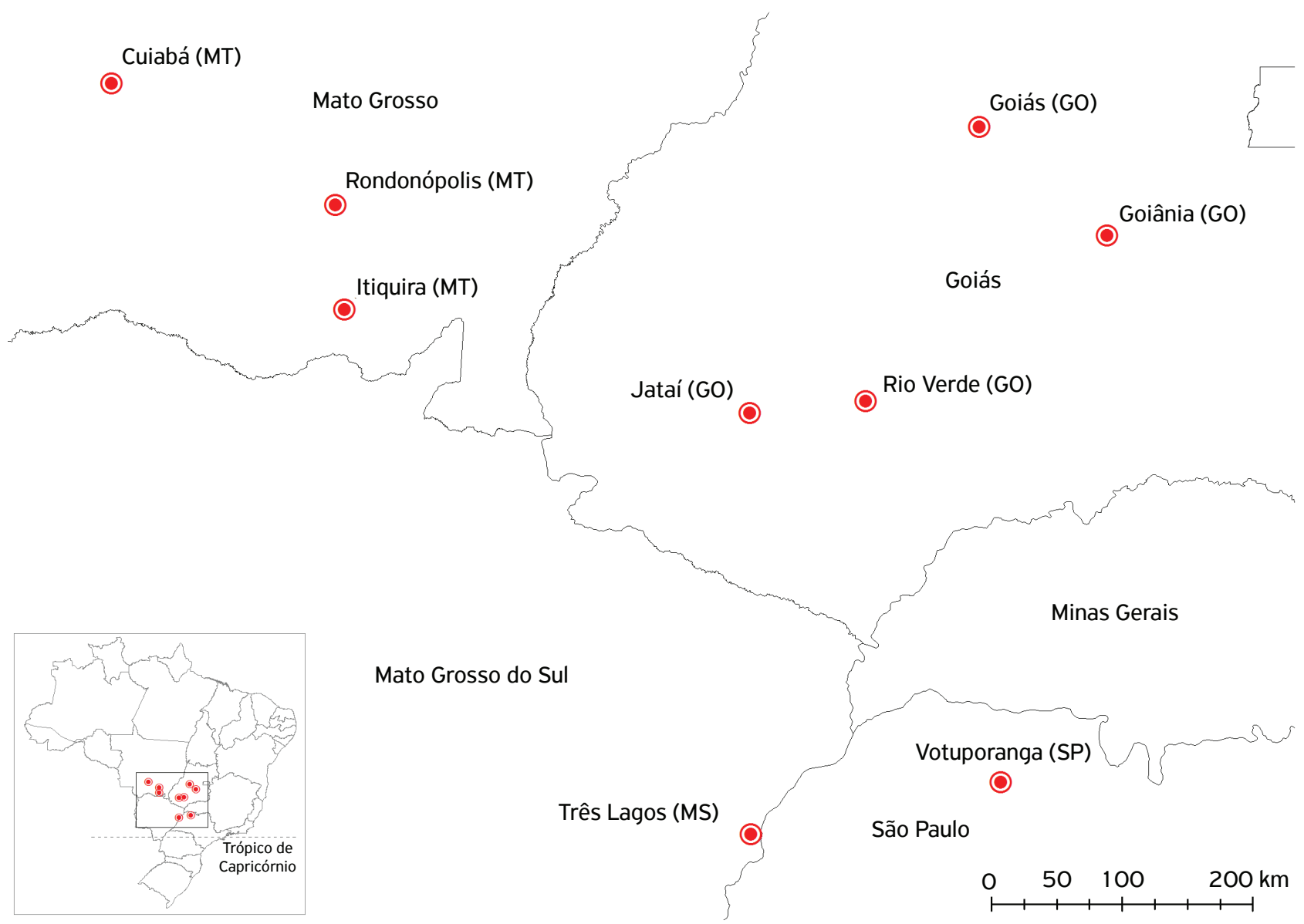

Figura 1. Localidades avaliadas das regiões de escape do mal das folhas.

Tabela 1. Normais climatológicas (1961-1990) e dados observados entre 12 de janeiro e 10 de fevereiro de 2013 das localidades avaliadas.

\begin{tabular}{|c|c|c|c|c|c|c|c|c|c|c|}
\hline \multirow{2}{*}{ Região } & Lat & Long & Alt & CK & $\mathrm{T}_{\mathrm{H}}$ & $T_{2013}$ & $\mathrm{UR}_{\mathrm{H}}$ & UR $_{2013}$ & $P_{H}$ & $P_{2013}$ \\
\hline & \multicolumn{2}{|c|}{ graus } & \multicolumn{2}{|l|}{ m } & \multicolumn{2}{|c|}{${ }^{\circ} \mathrm{C}$} & \multicolumn{2}{|c|}{$\%$} & \multicolumn{2}{|c|}{$\mathrm{mm}$} \\
\hline Votuporanga (SP) & $-20,42$ & $-49,98$ & 503 & Aw & 26,0 & 24,5 & 74,6 & 77,7 & 233 & 265 \\
\hline Três Lagoas (MS) & $-20,78$ & $-51,70$ & 313 & Aw & 26,0 & 26,3 & 74,6 & 73,2 & 233 & 224 \\
\hline Itiquira (MT) & $-17,17$ & $-54,50$ & 585 & Aw & 22,0 & 23,6 & 76,0 & 88,5 & 250 & 446 \\
\hline Rondonópolis (MT) & $-16,45$ & $-54,56$ & 284 & Aw & 25,2 & 24,9 & 80,0 & 84,9 & 309 & 341 \\
\hline Cuiabá (MT) & $-15,61$ & $-56,10$ & 145 & Aw & 28,0 & 25,7 & 81,0 & 82,0 & 216 & 230 \\
\hline Jataí (GO) & $-17,88$ & $-51,71$ & 663 & Aw & 26,5 & 23,3 & 80,0 & 84,9 & 290 & 212 \\
\hline Rio Verde (GO) & $-17,80$ & $-50,91$ & 775 & Aw & 23,4 & 22,3 & 79,5 & 85,5 & 233 & 481 \\
\hline Goiânia (GO) & $-16,66$ & $-49,25$ & 742 & Aw & 24,4 & 22,8 & 75,5 & 84,2 & 242 & 435 \\
\hline Goiás (GO) & $-15,91$ & $-50,13$ & 512 & $A w$ & 24,8 & 23,7 & 80,0 & 85,6 & 310 & 413 \\
\hline
\end{tabular}

Lat: latitude; Long: longitude; Alt: altitude; CK: classificação de Köppen; $T_{H}$ : temperatura do ar média histórica dos meses de janeiro e fevereiro; $\mathrm{T}_{2013}$ : temperatura observada entre 12 de janeiro e 10 de fevereiro de 2013; UR fevereiro; $\mathrm{UR}_{2013}$ : umidade relativa entre 12 de janeiro e 10 de fevereiro de 2013 ; $\mathrm{P}_{\mathrm{H}}$ : precipitação histórica nos meses de janeiro e fevereiro; $\mathrm{P}_{2013}$ : precipitação observada entre 12 de janeiro e 10 de fevereiro de 2013. 
Analisando-se os critérios para o NHT (critério: $20 \leq \mathrm{T}$ $\leq 25^{\circ} \mathrm{C}$ ) associado ao NHUR (critério: UR $\geq 90 \%$ ), e também para o NHP (critério: $\mathrm{P} \geq 1 \mathrm{~mm}$ ), observou-se uma maior frequência nas regiōes de Itiquira (MT), Rondonópolis (MT), Jataí (GO), Rio Verde (GO), Goiânia (GO) e Goiás (GO), com 20 h ou mais com $\mathrm{T}$ entre 20 e $25^{\circ} \mathrm{C}, 16 \mathrm{~h}$ ou mais de UR $\geq 90 \%$ e 8 h ou mais de $\mathrm{P} \geq 1 \mathrm{~mm}$, indicando que no período analisado, entre 12 de janeiro e 10 de fevereiro de 2013, essas regióes estavam mais sujeitas à incidência do mal das folhas devido às condiçóes ambientais mais favoráveis à doença (Figs. 2 a 4).

Nota-se que essas regióes não estáo submetidas a esses índices pluviométricos bem acima dos valores normais nessa época do ano (Tabela 1). Essas condiçôes, associadas a T e UR, que foram alteradas devido aos altos índices e por períodos contínuos de chuva acima de $1 \mathrm{~mm}$ entre 4 e 8 h, criaram condiçôes climáticas favoráveis à infecção.

O clima (temperatura e período de molhamento foliar) influencia significativamente no patossistema Hevea sp. versus M. ulei. A infecção por $M$. ulei em folhas jovens da seringueira ocorre em temperatura ideal da doença, em torno de $24^{\circ} \mathrm{C}$. Porém, Gasparotto (1988) verificou que entre 20 e $28^{\circ} \mathrm{C}$ ocorreu a doença com número de lesóes foliares alto.
Segundo Junqueira (1985), o M. ulei pode infectar a seringueira a $16^{\circ} \mathrm{C}$ e a doença pode evoluir normalmente quando essa temperatura atingir os $24^{\circ} \mathrm{C}$, mostrando que a temperatura de $16^{\circ} \mathrm{C}$ não impede que o patógeno penetre nas folhas de seringueira, mas a colonização se torna lenta ou paralisada.

Conforme Gasparotto (1988), a infecção da seringueira pelo mal das folhas pode ocorrer com $6 \mathrm{~h}$ de molhamento foliar a $24^{\circ} \mathrm{C}$, pois depende muito da virulência dos isolados e do tipo de clone da seringueira, se é suscetível ou resistente. Além disso, o autor destacou que as localidades poderiam estar sujeitas a orvalho, neblinas ou chuvas de pequena intensidade por períodos prolongados, oferecendo condiçóes extremamente favoráveis à ocorrência do mal das folhas.

Quanto maior for o período com temperaturas baixas, menor será a severidade da doença, pois a sensibilidade a baixas temperaturas também depende do patógeno (GASPAROTTO, 1988). A doença apresenta melhor correlação com o período de molhamento foliar e com a UR $\geq 90 \%$, porém ressalta-se que depende do tipo do patógeno, pois existem evidências de alta variabilidade fisiológica e do surgimento de novas raças de M. ulei mais virulentos, além do tipo de clone de seringueira sendo resistente ou suscetível.

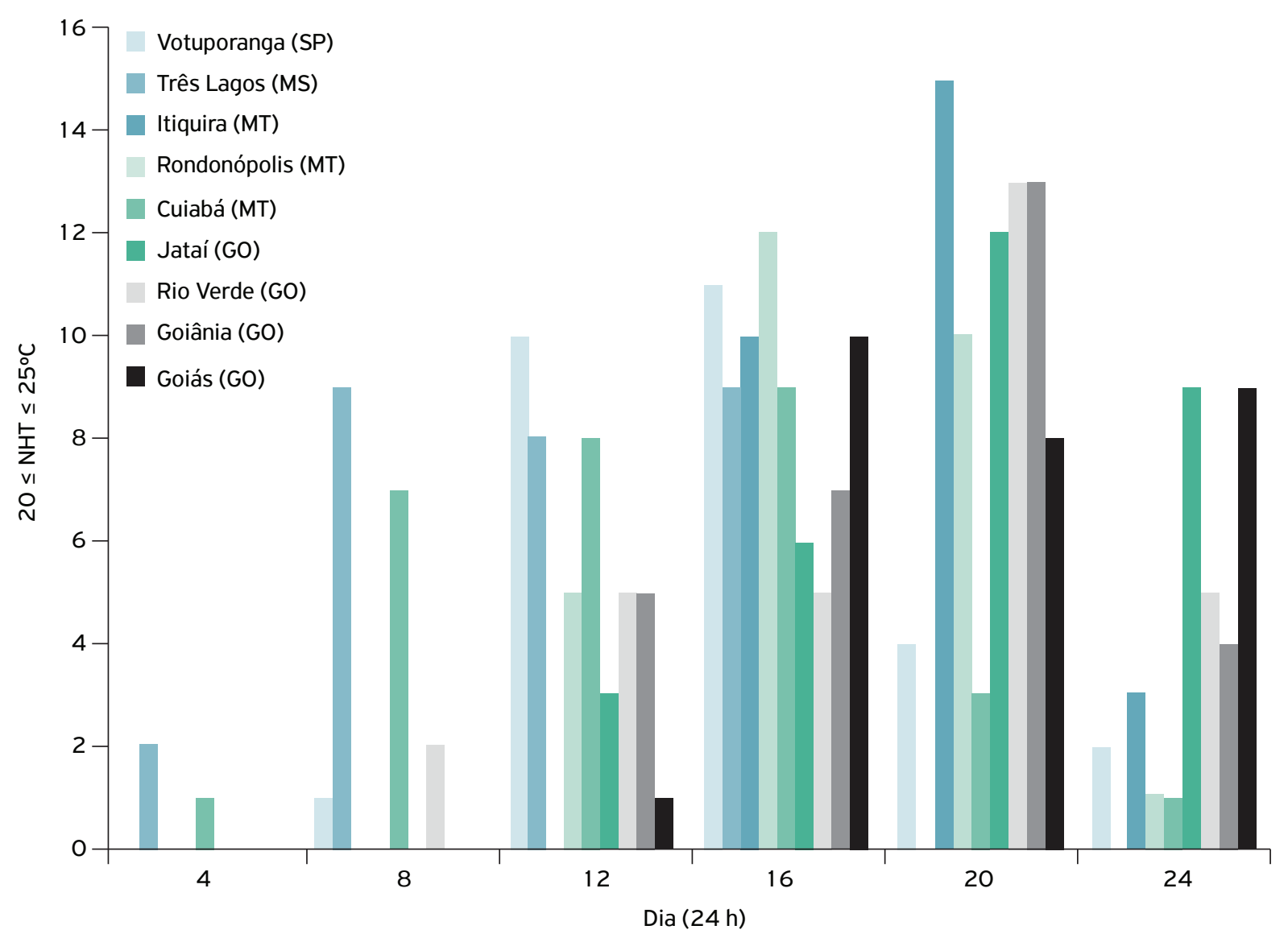

NHT: número de horas de temperatura do ar.

Figura 2. Distribuição da frequência diária do número de horas de temperatura do ar no intervalo entre 20 e $25^{\circ} \mathrm{C}$, no período entre 12 de janeiro e 10 de fevereiro de 2013. 


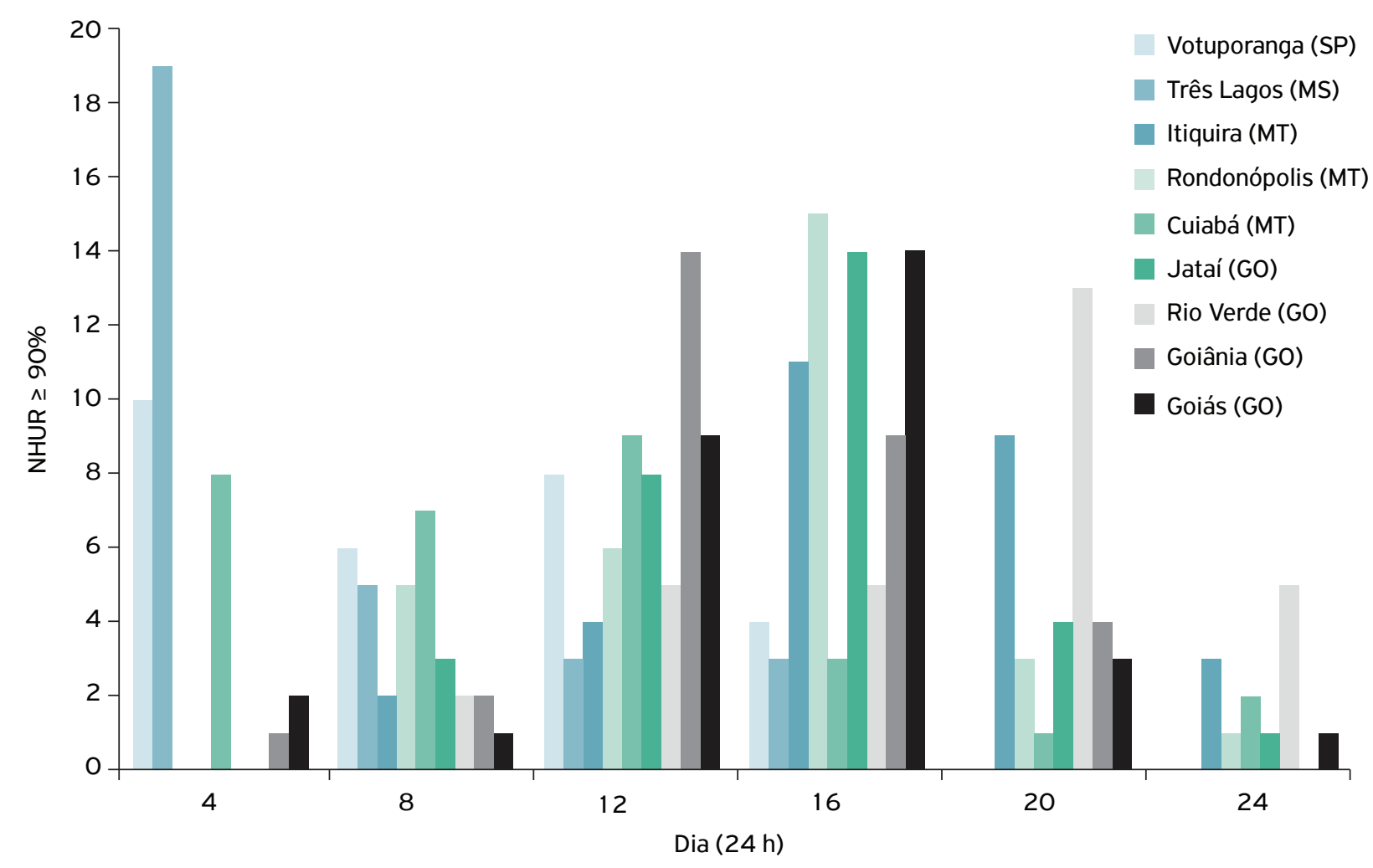

NHUR: número de horas de umidade relativa do ar.

Figura 3. Distribuição da frequência diária do número de horas de umidade relativa do ar igual ou maior que $90 \%$, no período entre 12 de janeiro e 10 de fevereiro de 2013.

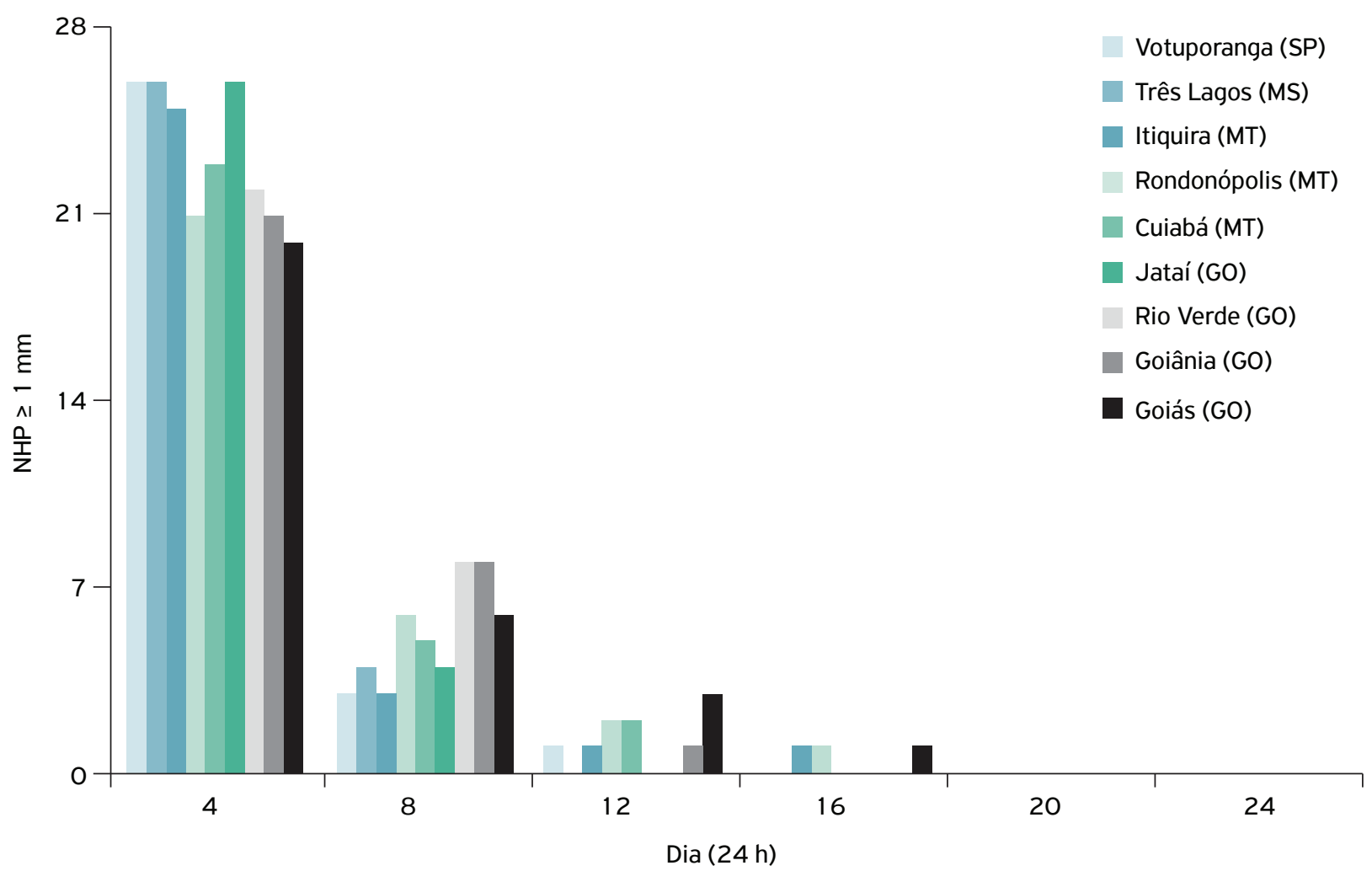

NHP: número de horas de precipitação pluviométrica.

Figura 4. Distribuição da frequência diária do número de horas de precipitação pluviométrica igual ou maior que $1 \mathrm{~mm}$, no período entre 12 de janeiro e 10 de fevereiro de 2013. 
Ortolani (1986) salientou que o hábito deciduifólio da seringueira é considerado importante, pois reduz o inóculo inicial, localizado nas folhas mais velhas, e uniformiza as brotaçóes, muito importantes nas áreas de escape, onde o refolhamento coincide com o período de baixo molhamento foliar, desfavoráveis ao desenvolvimento do patógeno.

Portanto, além dos fatores climáticos, vários outros aspectos estão associados ao mal das folhas, pois essa doença depende, além do clima (T e UR), da virulência do M. ulei, da suscetibilidade da seringueira, da localizaçáo do plantio, do período de troca de folhas e da presença do inóculo (esporos) da doença.

Um fenômeno interessante que tem se tornado frequente nos últimos anos é a chamada Zona de Convergência do Atlântico Sul (ZCAS), definida como uma regiấo de extensa faixa e bandas de nuvens formadas desde a Amazônia, CentroOeste e Sudeste (CARvalho; Jones, 2009). Essa característica climatológica está associada com chuvas ora fortes, ora moderadas, ora intermitentes, que persistem por, no mínimo, quatro dias e podem causar grandes transtornos, tais como alagamentos, inundaçóes, desabamentos e transbordamentos, em sua área de abrangência.

Climatologicamente, o sistema ZCAS é responsável pela grande quantidade de chuva de verão entre as regióes CentroOeste, Sudeste, partes do Norte e do Nordeste, ocasionando esse acúmulo de umidade, durante o veráo, o que deve ter favorecido essa epidemia de mal das folhas observada no início do ano em SP, MS, MT e GO. Por outro lado, a ausência desse sistema causa forte redução nas chuvas nessas regióes, tendo como consequência perdas na produção agrícola e risco de racionamento de água e de energia.

Como o fenômeno da ZCAS é comum no Brasil, espera-se que em outros anos em que houver um período muito úmido coincidindo com a presença de folhas novas de seringueira poderá haver novas epidemias de mal das folhas, como essa que ocorreu em 2013, pois a presença do patógeno, em baixas intensidades, é comum mesmo nas zonas de "escape". Recomenda-se aos produtores, para os próximos anos, acompanhar os informes meteorológicos e continuar observando o estágio fenológico do seringal, para futuras tomadas de decisão quanto ao controle do mal das folhas. A utilização de clones produtivos e resistentes ao mal das folhas é bem-vinda, mesmo para as zonas de "escape".

\section{AGRADECIMENTOS}

Ao Instituto Nacional de Meteorologia (INMET), pelos dados meteorológicos.

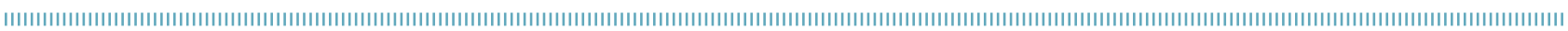
REFERÊNCIAS

ALVARES, C.A.; STAPE, J.L.; SENTELHAS, P.C.; GONÇALVES, J.L.M.; SPAROVEK, G. Köppen climate classification map for Brazil. Meteorologische Zeitschrift, in press, 2013.

CARVALHO, L.M.V.; JONES, C. Zona de Convergência do Atlântico Sul. In: CAVALCANTI, I.F.A.; FERREIRA, N.J.; SILVA, M.G.A.J.; DIAS, M.A.F.S. (Org.). Tempo e Clima no Brasil. São Paulo: Oficina de Textos, 2009. p.95-109.

GASPAROTTO, L. Epidemiologia do mal das folhas (Microcyclus ulei (P. Henn.) v. Arx) da seringueira (Hevea spp.). 1988, $124 \mathrm{p}$. Tese (Doutorado) - Universidade Federal de Viçosa, Viçosa, 1988.

INMET. Instituto Nacional de Meteorologia. Normais Climatológicas do Brasil 1961-1990. RAMOS, A.M.; SANTOS, L.A.R; FORTES, L.T.G. (Org.). Brasília: INMET, 2009. 465p.
INMET. Instituto Nacional de Meteorologia. Estação Meteorológica de Observação de Superfície Automática. 2013. Disponível em <http://www.inmet.gov.br/portal/index.php? r=estacoes/ estacoesAutomaticas>. Acesso em: 10 jul. 2013.

JUNQUEIRA N.T.V. Variabilidade fisiológica de Microcyclus ulei (P. Henn.) v. Arx. 1985, 135p. Tese (Doutorado) - Universidade Federal de Viçosa, Viçosa, 1985.

ORTOLANI, A.A. Agroclimatologia e cultivo da seringueira. In: SIMPÓSIO SOBREA CULTURA DA SERINGUEIRA NO ESTADO DE SÃO PAULO, 1. 1986, Piracicaba. Anais... Campinas: Fundação Cargil, 1986. p.11-31.

SENTELHAS, P.C.; DALLA MARTA, A.; ORLANDINI, S.; SANTOS, E.A.; GILLESPIE, T.J.; GLEASON, M.L. Suitability of relative humidity as an estimator of leaf wetness duration. Agricultural and Forest Meteorology, v.148, p.392-400, 2008. 